\title{
PROPAGAÇÃO VEGETATIVA DE Cordia trichotoma (VELL.) ARRAB. EX STEUDEL POR ESTAQUIA RADICULAR ${ }^{1}$
}

\author{
Paula Kielse ${ }^{2}$, Dilson Antônio Bisognin ${ }^{3}$, Michele Heberle ${ }^{2}$, Frederico Dimas Fleig ${ }^{2}$, Alencar Xavier ${ }^{5}$ e
} Marcelo Artur Rauber ${ }^{4}$

\begin{abstract}
RESUMO - Louro-pardo (Cordia trichotoma (Vell.) Arrab. ex Steudel) é espécie arbórea que possui raízes gemíferas, nas quais, após a ocorrência de distúrbios de origem natural ou antrópica, ocorre a formação de brotos. Nessa espécie, ao considerar a habilidade natural de regeneração pelo sistema radicular, presume-se que esses propágulos constituem material com elevado potencial morfogenético. O objetivo deste trabalho foi avaliar a propagação vegetativa de louro-pardo por estaquia radicular. No primeiro experimento, raízes de mudas de louro-pardo foram seccionadas em estacas com 5,0 cm de comprimento, classificadas quanto ao diâmetro em grossas $(1,6-2,5 \mathrm{~cm})$ e finas $(1,0-1,5 \mathrm{~cm})$ e tratadas em solução de $0,10,20$ e $30 \mathrm{mM}$ de AIB, por $10 \mathrm{seg}$. No segundo experimento, os propágulos foram classificados quanto à posição de coleta na raiz das mudas em basais, medianas e apicais, seccionadas em estacas de 1,0; 3,0 e 5,0 cm de comprimento e tratadas em solução de $30 \mathrm{mM}$ de AIB. O uso de AIB favoreceu o enraizamento das estacas radiculares, com maiores respostas nos tratamentos com a dose de $30 \mathrm{mM}$. Estacas radiculares com maior diâmetro mostraram-se mais aptas à brotação quando comparadas com as estacas radiculares menos espessas. As melhores respostas de brotação e enraizamento ocorreram em estacas radiculares basais e medianas com 3,0 e 5,0 cm de comprimento. Portanto, é possível realizar a propagação vegetativa de louro-pardo pela técnica de estaquia radicular.
\end{abstract}

Palavras-chave: Espécie arbórea, Estacas radiculares, Louro-pardo, Produção de mudas.

\section{VEGETATIVE PROPAGATION OF Cordia trichotoma (VELL.) ARRAB. EX STEUDEL FROM ROOT CUTTINGS}

\begin{abstract}
Cordia trichotoma (Vell.) Arrab. ex Steudel is a tree species that has roots with buds and, after the occurrence of natural or anthropic disturbances, sprouts develop from these buds. Considering the natural ability of regeneration by root system, it is assumed that these propagules contain tissues with high morphogenetic potential. The objective of this study was to evaluate the vegetative propagation of $\mathrm{C}$. trichotoma root cuttings. In the first experiment, seedling roots were sectioned into $5.0 \mathrm{~cm}$-long cuttings, classified into thick $(1.6-2.5 \mathrm{~cm})$ and thin $(1.0-1.5 \mathrm{~cm})$ according to its diameter. The root cuttings were treated in a solution of $0,10,20$ or $30 \mathrm{mM}$ IBA for 10 seconds. In the second experiment, roots were classified into basal, median and apical according to the position of collection and cut in cuttings with $1.0,3.0$ and $5.0 \mathrm{~cm}$ of length. The root cuttings were treated in a solution of $30 \mathrm{mM}$ IBA. The use of IBA favored rooting of root cuttings, with the highest responses in treatments with a dose of $30 \mathrm{mM}$. Thick root cuttings had a greatest potential for sprouting when compared to thin root cuttings. The highest responses of sprouting and rooting occurred in basal and median root cuttings with 3.0 and $5.0 \mathrm{~cm}$ length. In conclusion, it is possible to perform the vegetative propagation of $\mathrm{C}$. trichotoma by the technique of root cuttings.
\end{abstract}

Keywords: Cordia trichotoma, Root cuttings, Seedling production, Tree species.

\footnotetext{
${ }^{1}$ Recebido em 22.08.2012 aceito para publicação em 19.12.2012

${ }^{2}$ Programa de Pós-Graduação em Engenharia Florestal, Universidade Federal de Santa Maria, Brasil. E-mail: <paulinhakielse@ gmail.com>, <mheberle@gmail.com>e <fdfleig@smail.ufsm.br>.

${ }_{3}^{3}$ Departamento de Fitotecnia, Universidade Federal de Santa Maria, Brasil. E-mail: <dilsonb@smail.ufsm.br>.

${ }^{4}$ Graduando do Curso de Engenharia Florestal, Universidade Federal de Santa Maria, Brasil. E-mail: <rauber.ma@ gmail.com>.

${ }^{5}$ Graduando do Curso de Agronomia, Universidade Federal de Santa Maria, Brasil. E-mail: <alenxav@ gmail.com>.
} 


\section{INTRODUÇÃO}

O louro-pardo (Cordia trichotoma (Vell.) Arrab. ex Steud.) é espécie arbórea, pertencente à família Boraginaceae, que ocorre desde o Nordeste até o Sul do Brasil. É uma das espécies promissoras para plantios com fins comerciais, por apresentar uma combinação de aspectos favoráveis, entre os quais se destacam a boa forma de fuste e a madeira de excelente qualidade (RIZZINI, 1971). Aárvore possui qualidades ornamentais e pode ser empregada no paisagismo. É também indicada para reflorestamentos heterogêneos na recuperação de áreas degradadas (LORENZI, 2008).

Quanto à produção de mudas de louro-pardo, a propagação via sementes tem sido dificultada pela rápida perda da viabilidade, ocasionada pelo comportamento recalcitrante ao armazenamento. As sementes de louropardo apresentam, também, dormência tegumentar e germinação lenta e irregular (CARVALHO, 2006), o que dificulta a produção uniforme de mudas. No que se refere à propagação vegetativa, ainda não foi possível estabelecer um protocolo eficiente para a produção de mudas. Em estacas de ramos adultos de louro-pardo, com $10 \mathrm{~cm}$ de comprimento, o tratamento com $40 \mathrm{mM}$ de ácido indolbutírico (AIB) possibilitou satisfatória indução de brotos, mas não foi verificada a formação de raízes (HEBERLE et al., 2010). Em microestacas de louro-pardo cultivadas in vitro em meio de cultura contendo 7,38 $\mu \mathrm{M}$ de AIB também houve satisfatória indução de brotos, mas não ocorreu o enraizamento (FICK, 2007).

Algumas espécies arbóreas, a exemplo do louropardo, possuem raízes com células capazes de se desdiferenciar em pontos de crescimento meristemático, formando novos brotos e raízes (HARTMANN et al., 2010). Apesar da reconhecida importância de trabalhos que abordam a regeneração de estacas radiculares, especialmente de espécies gemíferas que apresentam estacas de ramos pouco responsivas ao enraizamento, são escassos os estudos sobre esse tema. Em estacas radiculares adultas de louro-pardo com $5 \mathrm{~cm}$ de comprimento, o tratamento com 20, 40 ou 60 mM de AIB não induziu a formação de raízes (KIELSE, 2012), o que torna necessária a realização de estudos adicionais que elucidem os fatores que podem estar atuando nesse processo.

O tamanho de estacas radiculares tem sido determinante à brotação e ao enraizamento (GHANI; CAHALAN, 1991; STENVALL et al., 2006; KY-DEMBELE et al., 2010; SNEDDEN et al., 2010). Em muitos casos,

Revista Árvore, Viçosa-MG, v.37, n1., p.59-66, 2013 estacas pequenas maximizam a taxa de multiplicação, mas o uso pode ser limitado pela baixa quantidade de reservas necessárias para a formação de raízes. Já estacas compridas são mais propensas à desidratação, pela maior superfície exposta ao ambiente (LIMA et al., 2006). O diâmetro dos propágulos também define o conteúdo de reservas, sendo observado em estacas mais espessas maior teor de carboidratos, amido e demais substâncias (HARTMANN et al., 2010). Normalmente, raízes próximas ao colo da planta são mais grossas e se tornam mais delgadas em direção à extremidade distal do sistema radicular, o que pode alterar as respostas morfogenéticas, conforme a posição de coleta.

O estímulo hormonal e a disponibilidade de fotoassimilados também são fatores que podem influenciar no enraizamento de estacas (PERES; KERBAUY, 2000). Entre as auxinas utilizadas para auxiliar o enraizamento adventício, destaca-se o ácido indolbutírico (AIB), pela sua ação pouco tóxica na maioria das plantas, mesmo em altas concentrações, além de ser fotoestável e pouco suscetível à ação dos sistemas enzimáticos de degradação das auxinas (EPSTEIN; LAVEE, 1984). Diversos estudos têm avaliado o efeito do AIB no enraizamento de estacas caulinares de espécies arbóreas (ALMEIDA et al., 2007; PIVETA et al., 2012), mas são escassos os estudos que abordam o uso dessa auxina no tratamento de estacas radiculares.

O objetivo deste trabalho foi avaliar o potencial de brotação e enraizamento de estacas radiculares de louro-pardo em razão da posição de coleta no sistema radicular, do comprimento e diâmetro das estacas e do uso de ácido indolbutírico.

\section{MATERIAL E MÉTODOS}

Este trabalho foi desenvolvido em casa de vegetação climatizada do Núcleo de Melhoramento e Propagação Vegetativa de Plantas, Departamento de Fitotecnia da Universidade Federal de Santa Maria, em Santa Maria, RS. Neste trabalho foram realizados dois experimentos, utilizando-se raízes de plantas de louro-pardo de origem seminal e com 3 anos de idade.

\subsection{Influência do diâmetro das estacas radiculares e das doses de AIB na brotação e enraizamento adventício de louro-pardo}

Raízes de plantas de louro-pardo foram seccionadas em estacas de 5,0 cm de comprimento e classificadas, quanto ao diâmetro, em grossas $(1,6-2,5 \mathrm{~cm})$ e finas $(1,0-1,5 \mathrm{~cm})$. O terço apical da raiz não foi utilizado 
no preparo das estacas. Para o enraizamento, as estacas radiculares tiveram a porção basal de suas bases imersas em solução de 10, 20 ou $30 \mathrm{mM}$ de AIB, por $10 \mathrm{seg}$. $\mathrm{O}$ tratamento controle foi constituído apenas por água destilada e álcool na proporção 1:1 (v/v). Após, as estacas foram cultivadas na posição vertical em bandejas de polietileno $(55 \times 34 \times 15 \mathrm{~cm})$ contendo mistura de substrato comercial à base de casca de pinus, casca de arroz carbonizada e areia grossa (1:1:1 v/v/). A base da estaca radicular corresponde à porção mais próxima da coifa. Para o preparo da solução de AIB, a auxina foi previamente dissolvida em álcool etílico $\left(98^{\circ} \mathrm{GL}\right)$ e diluída em água destilada, na proporção $1: 1(\mathrm{v} / \mathrm{v})$. O experimento foi conduzido durante os meses de abril a junho de 2010, em fatorial 2 × 4 (diâmetro da estaca e dose de AIB), no delineamento em blocos casualizados com oito repetições de cinco estacas por parcela. Aos 30 e 60 dias de cultivo, avaliaram-se as porcentagens de brotação, enraizamento e sobrevivência das estacas e o número e comprimento de brotos e raízes $(\mathrm{cm})$.

\subsection{Influência da posição de coleta e do comprimento das estacas radiculares na brotação e enraizamento adventício de louro-pardo}

Raízes de plantas de louro-pardo foram classificadas quanto à posição de coleta na raiz (basais, medianas e apicais) e seccionadas em estacas de 1,0; 3,0 e 5,0 $\mathrm{cm}$ de comprimento. As estacas radiculares tiveram suas bases imersas em solução de $30 \mathrm{mM}$ de AIB, por $10 \mathrm{seg}$. As estacas foram cultivadas nas mesmas condições descritas no item 2.1 .

O experimento foi conduzido durante os meses de setembro a dezembro de 2010 em fatorial 3 x 3 (posição de coleta e comprimento das estacas), no delineamento de blocos casualizados com seis repetições de cinco estacas por parcela. Aos 60 e 90 dias de cultivo, foram avaliados as porcentagens de brotação, enraizamento e sobrevivência das estacas, o número e comprimento de brotos e raízes $(\mathrm{cm})$ e o comprimento de brotos e raízes $(\mathrm{cm})$ por volume de estaca.

Todas as estacas radiculares tiveram os diâmetros medidos, sendo essa medição realizada na porção central da estaca. Para o cálculo do volume das estacas, utilizou-se a equação $v=\left(\pi \frac{d^{2}}{4}\right) . L$, sendo $d=$ diâmetro da estaca $(\mathrm{cm})$ e $\mathrm{L}=$ comprimento da estaca $(\mathrm{cm})$.

\subsection{Condições de cultivo e análise estatística}

O cultivo foi realizado em câmara úmida com umidade relativa do ar mantida em aproximadamente $85 \%$, com o auxílio de um climatizador acionado automaticamente 12 vezes ao dia, durante $15 \mathrm{~min}$, com fluxo de ar de $10 \mathrm{~m}^{3} / \mathrm{min}$. A temperatura média no interior da câmara úmida foi de $27^{\circ} \mathrm{C}$.

Os dados foram submetidos à análise de variância com o programa ESTAT (UNESP - Jaboticabal). As médias dos tratamentos qualitativos foram comparadas pelo teste de Tukey $(\leq 0,05)$ e os tratamentos quantitativos, por análise de regressão. Para atender aos pressupostos da normalidade, os dados de porcentagem foram transformados para arcosseno $\sqrt{\mathrm{x} / 100}$ e de contagem e comprimento, para $\sqrt{\mathrm{x}+0,5}$.

\section{RESULTADOS}

No primeiro experimento não houve interação significativa entre o diâmetro das estacas e as doses de AIB $(\leq 0,05)$, em todas as variáveis analisadas. A porcentagem de enraizamento e o número de raízes foram influenciados apenas pelas doses de AIB, sendo o modelo quadrático o que melhor se ajustou para explicar o comportamento dessas variáveis (Figura 1). O tratamento constituído por estacas radiculares de louropardo tratadas com a dose de $30 \mathrm{mM}$ de AIB apresentou a maior porcentagem de enraizamento e o maior número de raízes, aos 30 e 60 dias de avaliação. A porcentagem de brotação, o número e comprimento dos brotos e o comprimento das raízes foram influenciados pelo diâmetro das estacas $(\leq 0,05)$, aos 60 dias de avaliação, sendo observado que estacas radiculares de maior diâmetro (1,6 - 2,5 cm) se mostraram superiores às estacas de menor diâmetro (Tabela 1).

No segundo experimento não foi verificada interação significativa entre a posição de coleta na raiz e o comprimento das estacas $(\leq 0,05)$ nas porcentagens de enraizamento e sobrevivência das estacas, número e comprimento das raízes. Houve influência da posição de coleta na raiz, com maior porcentagem de enraizamento e maior número e comprimento de raízes em estacas radiculares basais e medianas, que diferiram significativamente das estacas radiculares apicais (Tabela 2). Também foi verificado que as estacas radiculares com 3,0 e 5,0 cm de comprimento apresentaram melhores respostas de enraizamento, diferindo significativamente das estacas radiculares com 1,0 cm.

Revista Árvore, Viçosa-MG, v.37, n1., p.59-66, 2013
Revista Árvore, Viçosa-MG, v.37, n1., p.59-66, 2013

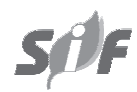


Não foi possível definir classes de diâmetro para a posição de coleta das estacas radiculares, em virtude da variação na estrutura do sistema radicular das plantas utilizadas como fonte de propágulos. Entretanto, foi verificada correlação positiva entre o volume $\left(\mathrm{cm}^{3}\right)$ das estacas e o comprimento dos brotos, aos 60 e 90 dias de avaliação (Figura 2). Para comprimento das raízes, observou-se reduzida tendência crescente da linha de regressão, indicando que não existe forte relação entre o volume das estacas radiculares e o comprimento das raízes.
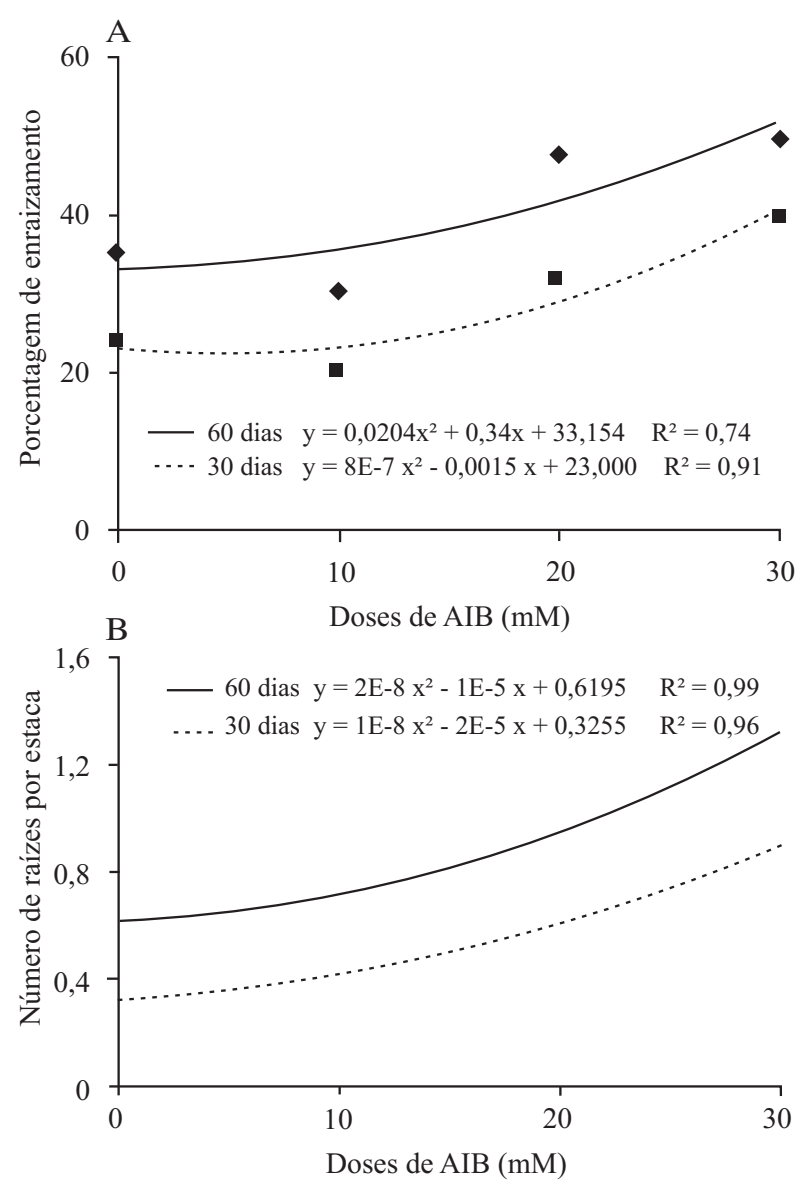

Figura 1 - Porcentagem de enraizamento (A) e número de raízes por estaca (B) em estacas radiculares grossas $(1,6-2,5 \mathrm{~cm})$ e finas $(1,0-1,5 \mathrm{~cm})$ de louropardo (Cordia trichotoma) em razão de diferentes doses de ácido indolbutírico (AIB), aos 30 e 60 dias de avaliação.

Figure 1 -Rooting percentage (A) and number of roots per cutting (B) of thick $(1.6-2.5 \mathrm{~cm})$ and thin $(1.0$ $1.5 \mathrm{~cm}$ ) root cuttings of Cordia trichotoma in function of indolbutyric acid (IBA) concentrations, evaluated after 30 and 60 days.
A porcentagem de sobrevivência foi influenciada pela posição de coleta na raiz e pelo tamanho das estacas. Estacas radiculares basais e medianas apresentaram os maiores índices de sobrevivência, sendo o mesmo verificado em estacas radiculares com 3,0 e 5,0 cm de comprimento (Figura 3 ). As estacas radiculares apicais apresentaram as menores taxas de sobrevivência, sendo o mesmo comportamento verificado em estacas radiculares com $1,0 \mathrm{~cm}$ de comprimento que, independentemente da posição de coleta, exibiram baixo potencial de sobrevivência.

\section{DISCUSSÃO}

Propágulos radiculares coletados de mudas de louro-pardo mostraram-se pouco aptos ao enraizamento, sendo necessário o uso de AIB para maximizar a formação de raízes adventícias. Estes resultados podem ser explicados pela ação da auxina no estabelecimento da competência e determinação das células-alvo (TAIZ; ZEIGER, 2008), o que acarretou aumento das respostas rizogênicas à medida que se elevaram as doses de AIB. Em estudo de cultivo in vitro, quando as doses de auxina são superiores às de citocinina, a resposta morfogenética está associada à formação de raízes e, quando as doses de citocinina são superiores às de auxina, ocorre a indução de parte aérea (SKOOG; MILLER, 1957). Assim, a maior indução de raízes em estacas radiculares de louro-pardo tratadas com AIB pode estar relacionada com a alta relação auxina/citocinina.

Apesar de conhecido que a aplicação exógena de auxinas auxilia no enraizamento adventício, sabe-se que esta resposta ocorre somente até uma dose máxima,

Tabela 1 - Porcentagem de brotação (PB), número de brotos (NB), comprimento de brotos e raízes (CB e CR) e sobrevivência (S) de estacas radiculares de louropardo (Cordia trichotoma), avaliados aos 60 dias.

Table 1 - Sprouting percentage (PB), number of sprouts (NB), length of shoots and roots (CB and $C R)$ and survival (S) of root cuttings Cordia trichotoma, evaluated at 60 days of age.

\begin{tabular}{lccccc}
\hline Diâmetro $(\mathrm{cm})$ & PB $(\%)$ & NB & CB $(\mathrm{cm})$ & CR $(\mathrm{cm})$ & $\mathrm{S}(\%)$ \\
\hline $1,6-2,5$ & $26^{\mathrm{a} *}$ & $0,30^{\mathrm{a}}$ & $2,27^{\mathrm{a}}$ & $5,40^{\mathrm{a}}$ & $54^{\mathrm{a}}$ \\
$1,0-1,5$ & $12^{\mathrm{b}}$ & $0,15^{\mathrm{b}}$ & $1,75^{\mathrm{b}}$ & $2,40^{\mathrm{b}}$ & $43^{\mathrm{a}}$ \\
Média & 19 & 0,22 & 2,01 & 3,90 & 48 \\
CV $(\%)$ & 65,59 & 13,13 & 40,85 & 33,96 & 37,44 \\
\hline
\end{tabular}

* Médias seguidas de letra diferente diferem-se pelo teste de Tukey a $5 \%$ de probabilidade de erro. 
Tabela 2 - Porcentagem de enraizamento (PE), número e comprimento de raízes (NR e CR) em estacas radiculares juvenis basais, medianas e apicais de louro-pardo (Cordia trichotoma) com 1,0; 3,0; e 5,0 cm de comprimento, aos 60 e 90 dias de avaliação.

Table 2 - Rooting percentage (RP), number and length of roots (NR and RL) of C. trichotoma basal, median and apical root cuttings with $1.0,3.0$ and $5.0 \mathrm{~cm}$ length, evaluated at 60 and 90 days of age.

\begin{tabular}{|c|c|c|c|c|c|c|}
\hline & \multicolumn{3}{|c|}{60 dias de avaliação } & \multicolumn{3}{|c|}{90 dias de avaliação } \\
\hline & $\mathrm{PE}(\%)$ & NR & $\mathrm{CR}(\mathrm{cm})$ & $\mathrm{PE}(\%)$ & NR & $\mathrm{CR}(\mathrm{cm})$ \\
\hline \multicolumn{7}{|l|}{ Posição } \\
\hline Basal & $15^{\mathrm{a}^{*}}$ & $0,33^{\mathrm{a}}$ & $1,83^{\mathrm{a}}$ & $18^{\mathrm{a}}$ & $0,65^{a}$ & $5,82^{a}$ \\
\hline Mediana & $16^{\mathrm{a}}$ & $0,25^{\mathrm{a}}$ & $3,45^{\mathrm{a}}$ & $17^{\mathrm{a}}$ & $0,41^{\mathrm{a}}$ & $6,17^{\mathrm{a}}$ \\
\hline Apical & $02^{\mathrm{b}}$ & $0,02^{\mathrm{b}}$ & $0,56^{\mathrm{b}}$ & $02^{\mathrm{b}}$ & $0,02^{\mathrm{b}}$ & $0,83^{\mathrm{b}}$ \\
\hline Média & 11,00 & 0,20 & 1,94 & 12,33 & 0,36 & 4,27 \\
\hline \multicolumn{7}{|c|}{ Comprimento } \\
\hline $5,0 \mathrm{~cm}$ & $19^{\mathrm{a}}$ & $0,37^{\mathrm{a}}$ & $2,45^{\mathrm{a}}$ & $19^{\mathrm{a}}$ & $0,67^{\mathrm{a}}$ & $4,76^{\mathrm{a}}$ \\
\hline $3,0 \mathrm{~cm}$ & $13^{\mathrm{b}}$ & $0,20^{\mathrm{ab}}$ & $2,20^{\mathrm{ab}}$ & $15^{\mathrm{b}}$ & $0,38^{\mathrm{ab}}$ & $4,24^{\mathrm{ab}}$ \\
\hline $1,0 \mathrm{~cm}$ & $02^{\mathrm{c}}$ & $0,02^{\mathrm{b}}$ & $1,20^{\mathrm{b}}$ & $02^{\mathrm{c}}$ & $0,02^{\mathrm{b}}$ & $3,83^{\mathrm{b}}$ \\
\hline Média & 11,33 & 0,19 & 1,95 & 12,00 & 0,35 & 4,27 \\
\hline CV (\%) & 78,78 & 19,26 & 49,12 & 90,76 & 27,91 & 62,17 \\
\hline
\end{tabular}

* Médias seguidas de letra diferente diferem-se pelo teste de Tukey a $5 \%$ de probabilidade de erro.
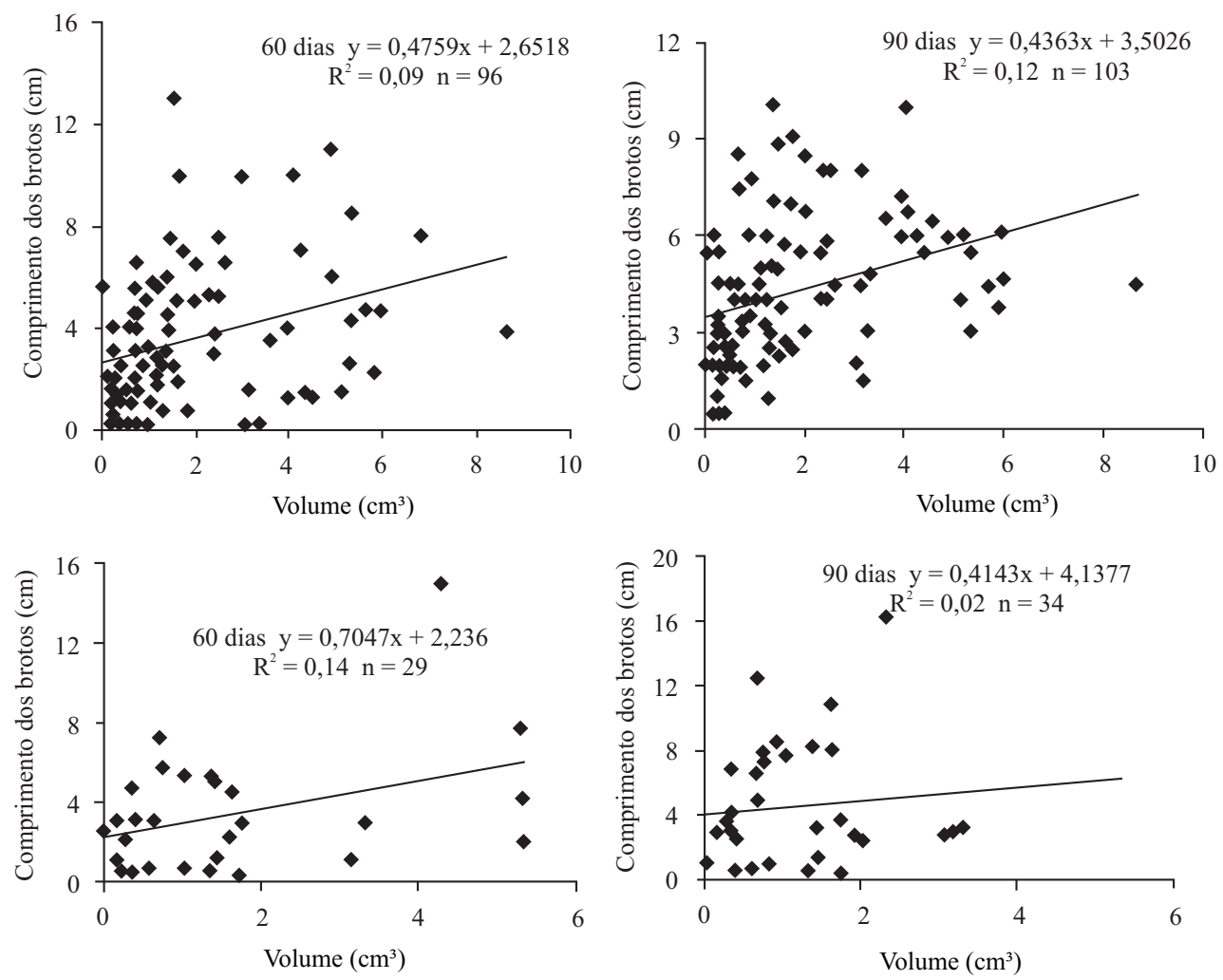

Figura 2 - Relação entre o volume das estacas radiculares de louro-pardo (Cordia trichotoma) e o comprimento dos brotos (superior) e relação entre o volume das estacas radiculares e o comprimento das raízes (inferior), aos 60 e 90 dias de avaliação.

Figure 2 - Relationship between the volume of root cuttings of Cordia trichotoma and length of shoot (above) and between the volume of root cuttings and root length (below), evaluated after 60 and 90 days of age. 
a partir da qual acontece o efeito fitotóxico (FACHINELLO et al., 2005). No caso do louro-pardo, houve tendência crescente das curvas de regressão até a dose de 30 mM de AIB (Figura 1), não sendo observada queda nos percentuais de enraizamento com o aumento da dose de auxina. Nesse caso, doses de AIB superiores às utilizadas neste estudo podem ser testadas, visando à obtenção do seu ponto de máxima eficiência técnica e à maximização do processo de produção de mudas de louro-pardo.

Em algumas espécies, o diâmetro das estacas pode influenciar a brotação e o enraizamento, pois estacas espessas apresentam maior teor de carboidratos, amido e demais substâncias nutritivas, se comparadas com
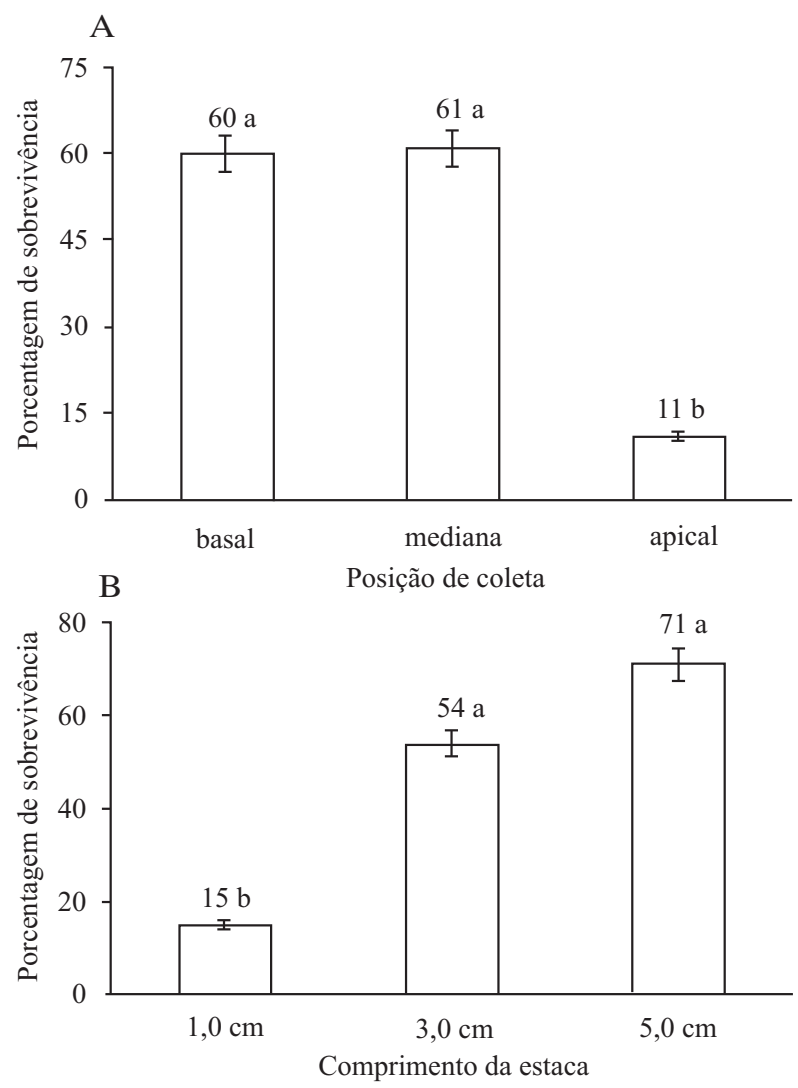

Figura 3 - Sobrevivência das estacas radiculares de louropardo (Cordia trichotoma) em razão da posição de coleta na raiz (A) e do comprimento das estacas (B), aos 90 dias de avaliação.

Figure 3 - Survival of root cuttings of Cordia trichotoma according to position of root collection (A) and cutting length $(B)$, evaluated at 90 days of age.

Revista Árvore, Viçosa-MG, v.37, n1., p.59-66, 2013 as estacas de menor diâmentro (HARTMANN et al., 2010). Para o louro-pardo, estacas de maior diâmetro (1,6 - 2,5 cm) mostraram maior aptidão para a brotação, mas esse fator não influenciou a indução das raízes adventícias. Em kiwi (Actinidia chinesis Planch.), estacas radiculares de 5 e $15 \mathrm{~cm}$ de comprimento de menores classes de diâmetro (inferior a $0,5 \mathrm{~cm}$ ) apresentaram a menor porcentagem de brotação (12\%), ao passo que as estacas de maior diâmetro $(0,5 \mathrm{a} 2,5 \mathrm{~cm})$ tiveram 48\% de brotação (LAWES; SIM, 1980). Já nas estacas radiculares do híbrido de álamo (Populus tremula x Populus tremuloides), com $3 \mathrm{~cm}$ de comprimento, o diâmetro das estacas não afetou o potencial de brotação, mas teve forte efeito no enraizamento adventício (STENVALL et al., 2006).

Estacas radiculares basais e medianas de louropardo mostraram maior capacidade de enraizamento e sobrevivência, se comparadas com as estacas apicais. Ao longo do sistema radicular pode existir diferença nos teores de carboidratos, aminoácidos e outras substâncias, podendo as respostas de brotação e enraizamento ser variáveis em razão da posição de coleta (HARTMANN et al., 2010). Além disso, células de estacas que possuem potencial endógeno para formação de raízes adquirem a competência, reagindo a sinais específicos, como fitormônios, luz e temperatura (GRATTAPAGLIA; MACHADO, 1998), o que pode explicar o maior potencial de enraizamento das estacas radiculares basais e medianas em relação às estacas apicais, embora ambas tenham sido tratadas com $6.000 \mathrm{mg} \mathrm{L}^{-1}$ de AIB.

Estacas radiculares basais e medianas, $\operatorname{com} 3,0$ e 5,0 cm de comprimento, podem ser empregadas para a produção de mudas de louro-pardo. Entretanto, dentro desse intervalo de comprimento, o uso de estacas menores maximiza o processo de produção de mudas, pelo aumento do número de estacas por planta. Assim, ao se considerar o potencial produtivo, as estacas radiculares de louro-pardo devem ser confeccionadas com 3,0 cm de comprimento. Estacas radiculares apicais devem ser eliminadas do processo, pelo baixo potencial morfogenético apresentado por esse tipo de material.

\section{CONCLUSÃO}

É possível realizar a propagação vegetativa de louro-pardo utilizando propágulos radiculares juvenis. $\mathrm{O}$ diâmetro das estacas radiculares influenciou as 
respostas de brotação e enraizamento adventício. A aplicação de ácido indolbutírico (AIB) favorece o enraizamento, sendo observadas as melhores respostas rizogênicas em estacas radiculares tratadas com $30 \mathrm{mM}$ de AIB. Estacas radiculares basais e medianas de 3 a $5 \mathrm{~cm}$ de comprimento podem ser utilizadas para a propagação vegetativa do louropardo.

\section{AGRADECIMENTOS}

À Coordenação de Aperfeiçoamento de Pessoal de Nível Superior (Capes) e ao Conselho Nacional de Desenvolvimento Científico e Tecnológico (CNPq), pela concessão de bolsas.

\section{REFERÊNCIAS}

ALMEIDA, F. D.; XAVIER, A.; DIAS, J. M. M. Propagação vegetativa de árvores selecionadas de Eucalyptus cloeziana F. Müell. por estaquia. Revista Árvore, v.31, n.3, p.445-453, 2007.

CARVALHO, P. E. R. Espécies arbóreas brasileiras. Brasília: Embrapa Informação Tecnológica/Colombo: Embrapa Florestas, 2006. v. 2. 628 p.

EPSTEIN, E.; LAVEE, S. Conversion of indole-3butyric acid to indole-3-acetic acid by cuttings of grapevine (Vitis vinifera) and olive (Olea europea). Plant and Cell Physiology, v.25, 5, p.697-703, 1984.

FACHINELLO, J. C.; HOFFMANN, A.; NACHTIGAL, J. C. (Ed.). Propagação de plantas frutíferas. Brasília: Embrapa Informações Tecnológicas, 2005. 221p.

FICK, T. A. Estabelecimento in vitro e propagação de Cordia trichotoma (Vell.) Arrabida ex Steudel (louro-pardo). 2007. 63 f. Dissertação (Mestre em Engenharia Florestal) - Universidade Federal de Santa Maria, Santa Maria, 2007.

GHANI, A.; CAHALAN, C. M. Propagation of Prunus avium from root cuttings. Forestry, n.64, v.4, p.403-409, 1991.
GRATTAPAGLIA, D.; MACHADO, M. A. Micropropagação. In: TORRES, A. C.; CALDAS, L. C.; BUSO, J. A (Ed.). Cultura de tecidos e transformação genética de plantas. Brasília: CBAB/Embrapa, 1998. p.183-260.

HARTMANN, H. T. et al. Plant propagation: principles and practices. New Jersey: Prentice Hall, 2010. 915p.

HEBERLE, M. et al. Estaquia de louro-pardo. In: JORNADAS TÉCNICA FORESTALES Y AMBIENTALES, 14., 2010, Missiones. Anais...Missiones: UNaM, 2010.

KIELSE, P. Propagação vegetativa de louro-pardo (Cordia trichotoma (Vell.) Arrab. ex Steud.) por estaquia radicular e miniestaquia. 118 f. 2012. Tese (Doutorado em Engenharia Florestal) Universidade Federal de Santa Maria, Santa Maria, 2012.

KY-DEMBELE, C. et al. Clonal propagation of Detarium microcarpum from root cuttings. Silva Fennica, v.44, n.5, p.775-786, 2010.

LAWES, G. S.; SIM, B. L. Kiwifruit propagation from root cuttings. New Zealand Journal of Experimental Agriculture, v.8, n.3-4, p.273-275, 1980.

LIMA, R. L. S. et al. Comprimento de estacas e parte do ramo na formação de mudas de aceroleira. Revista Brasileira de Fruticultura, v.28, n.1, p.83-86, 2006.

LORENZI, H. Árvores brasileiras: manual de identificação e cultivo de plantas arbóreas nativas do Brasil. 5.ed. Nova Odessa: Instituto Plantarum de Estudos da Flora, 2008. v.1. 384p.

PERES, L. E. P.; KERBAUY, G. B. Controle hormonal do desenvolvimento das raízes. Revista Universa, v.8, p.181-195, 2000.

PIVETA, K. F. L. et al. Época de coleta e ácido indolbutírico no enraizamento de estacas de espirradeira (Nerium oleander L.). Revista Árvore, v.36, n.1, p.17-23, 2012.

RIZZINI, C. T. Árvores e madeiras úteis do Brasil: manual de dendrologia brasileira. São Paulo: Edgar Blüncher, 1971. 294p.

Revista Árvore, Viçosa-MG, v.37, n1., p.59-66, 2013 
SKOOG, F.; MILLER, C. O. Chemical regulation of growth and organ formation in plant tissues cultured in vitro. Symposia of the Society for Experimental Biology, v.11, p.118-231, 1957.

SNEDDEN, J. et al. Propagating trembling aspen from root cuttings: impact of storage length and phenological period of root donor plants. New Forests, v.39, n.2, p.169-182, 2010.
STENVALL, N.; HAAPALA, T.; PULKKINEN, P. The role of a root cutting's diameter and location on the regeneration ability of hybrid aspen.

Forest Ecology and Management, v.237, n.1/3, p.150-155, 2006.

TAIZ, L.; ZEIGER, E. Fisiologia vegetal. 4.ed. Porto Alegre: Artmed, 2008. 820p. 